\title{
Acta Médica Colombiana y las fuerzas de producción social
}

\section{Acta Medica Colombiana and the social productive forces}

\author{
Eugenio MatiJASEVIC • Bogotá, D.C.
}

Las publicaciones científicas periódicas cumplen en la actualidad un papel fundamental como medios de comunicación e intercambio de conocimiento científico. Dicho conocimiento, sin embargo, no emerge de manera espontánea de la nada, sino que requiere seres humanos encargados de su producción en un proceso que, como todo proceso de producción social, consume recursos económicos.

Todas las personas involucradas en procesos de investigación, desde quienes construyen las edificaciones en donde se realizan, hasta quienes llevan a cabo el mantenimiento de las mismas, pasando obviamente por quienes trabajan en ellas haciendo las investigaciones, sean estas de física cuántica en un acelerador de partículas, de bioquímica en cultivos celulares, de fisiología en animales de laboratorio o experimentos clínicos a gran escala, doble ciego y aleatorizados, consumen un cierto porcentaje de los bienes de consumo producidos por la sociedad en su conjunto sin generar otros, puesto que las investigaciones, aunque en ciertos casos contribuyen a mediano o largo plazo a mejorar la producción de bienes de consumo, no los producen de manera directa.

Dado que los recursos económicos no son ilimitados, los investigadores (las personas encargadas al interior de la división social del trabajo de producir conocimientos) tienen que entrar a competir por esos recursos en una economía de mercado, en la que otros agentes económicos (que en ocasiones son otros investigadores) quieren para sí esos recursos.

De la misma manera que los procesos de investigación, también las publicaciones periódicas científicas consumen recursos económicos sin generarlos de manera directa y también ellas deben entrar a competir en el mercado por los escasos recursos económicos disponibles. Dicho mercado es ciego, confunde bienestar con consumo, y tampoco puede planear de manera precisa el futuro, de tal forma que está más centrado en producir y consumir bienes y servicios que en producir intangibles como el conocimiento (incluso cuando sus agentes saben que a largo plazo ese conocimiento puede redundar en mejorar la producción).

Ahora bien, de la misma manera que el dinero (que en principio era solo un medio para equilibrar el intercambio de bienes y servicios como sustitución apenas obvia del trueque) se transforma en una mercancía sujeta a las mismas leyes de la oferta y la demanda que las demás mercaderías, las investigaciones científicas (que en un principio eran solo un medio para incrementar nuestra capacidad de predecir los eventos del mundo y para incrementar nuestra capacidad de transformar objetos materiales en productos del trabajo y en bienes de consumo) se han convertido a su vez en mercancías y, de paso, las publicaciones periódicas científicas (que en un principio eran solo un medio para intercambiar los conocimientos generados por las investigaciones científicas) también se han transformado en bienes mercadeables (1). Como mercancías, tanto las investigaciones como las publicaciones periódicas científicas están sujetas a las mismas leyes de la producción y del mercado que estudiaron Adam Smith, David Ricardo, Karl Marx y John Maynard Keynes, y no pueden escapar a las fuerzas económicas que rigen el sistema de producción social.

Dichas fuerzas económicas, que Adam Smith definió como los motores fundamentales de toda economía de mercado, son el interés (egoísta) de los particulares, la competencia entre diversos particulares con intereses disímiles y el equilibrio o desequilibrio entre la oferta y
Acta Med Colomb 2010; 35: 107-112.

Dr. Eugenio Matijasevic: Editor General Acta Médica Colombiana

Correspondencia: eugenio.matijasevic@gmail.co Recibido: 12/X/2010 Aceptado 12/X/2010 
la demanda (2). Son estas tres fuerzas las que determinan la posibilidad de que una empresa económica (y prácticamente no hay empresa humana que en última instancia no lo sea) alcance o no la meta que todas se proponen: conseguir para sus propietarios la mayor cantidad posible de los escasos recursos económicos disponibles.

Adam Smith estaba convencido de la bondad intrínseca de las fuerzas del mercado y llegó a prometer que, dejándolas desatadas, terminarían por sí solas por equilibrarse $\mathrm{y}$ autorregularse unas a otras, de tal manera que la justicia surgiría de manera espontánea en su seno, asignando a cada uno con eficiencia y equidad tanto los recursos como los productos de la actividad económica gracias a una especie de "mano invisible"(3). Pero no tuvo en cuenta que los recursos económicos no son ilimitados y olvidó que las fuerzas del mercado (egoístas por esencia) no son la divina providencia (a pesar de la mano invisible). Pero quienes creían, por oposición a Adam Smith, que la generación espontánea de la justicia en el libre mercado era un imposible y que más bien el sistema tendería a autorregularse hacia un status quo neutro en el que, si bien no surgiría la justicia, no surgiría tampoco otra cosa, estaban igualmente equivocados. Está plenamente demostrado, la historia lo atestigua, que, dejadas a la deriva, las fuerzas del mercado generan de manera creciente la desigualdad y la injusticia.

Una buena forma de alcanzar la meta de conseguir para los propietarios de una empresa económica la mayor cantidad posible de los escasos recursos económicos disponibles es, utilizando los vientos de las fuerzas del mercado a su favor, garantizar la satisfacción del cliente. Un sastre, una fábrica de zapatos, tienen que producir mercancías a la medida del cliente o no lograrán venderlas.

A partir de las anteriores premisas es fácil comprender (aunque no aprobar) que, enfrentadas a los vaivenes de las fuerzas del mercado, algunas empresas dedicadas a la investigación, temerosas de no rendir los réditos esperados o ávidas de rendir más de lo esperable, estén dispuestas a vender su mercancía (la investigación) al mejor postor y, a veces, estén dispuestas a aceptar que su mercancía sea fabricada a la medida del postor. También algunas empresas dedicadas a la edición, impresión, difusión y comercialización de publicaciones periódicas científicas, están dispuestas a vender su mercancía (la divulgación de investigaciones) al mejor postor y dispuestas, además, a aceptar que (como las sastrerías y las fábricas de zapatos) el producto sea hecho a la medida del postor. Acta Médica Colombiana no es una de ellas.

Es indudable que una investigación puede (y debe) hacerse a partir de las necesidades de conocimiento que tiene quien paga la investigación, pero los resultados no pueden construirse para colmar las necesidades comerciales del cliente. El ejemplo más claro de esta situación se presenta en las investigaciones sobre medicamentos. Para nadie es un secreto que el objetivo primario de las empresas que producen medicamentos no es mejorar la salud de los enfermos, la verdadera meta es que sus productos (mercancías) se vendan más con el fin de aumentar las ganancias de los accionistas. Obviamente, nada impide que ambas cosas vayan de la mano: si el medicamento verdaderamente mejora la salud, seguramente se venderá más (lo segundo como consecuencia de la difusión de información fidedigna con respecto a lo primero). Pero en ocasiones no ocurre necesariamente así, sino que es posible difundir la información sesgada o amañada o incluso fraudulenta de que el medicamento mejora la salud, sustentándola en investigaciones científicas fabricadas a la medida del cliente (y que por tanto son, a su vez, sesgadas o amañadas o incluso fraudulentas) para que el medicamento se venda más.

Puesto que a la hora de elegir una mercancía, así esta sea un medicamento, la publicidad influye de manera insoslayable, nada impide que las fuerzas del mercado utilicen las publicaciones periódicas científicas, habitualmente vehículos de difusión del conocimiento, como vehículos de difusión publicitaria. No es infrecuente, por tanto, que algunas investigaciones científicas no sean tales, sino que, fabricadas a la medida del postor, sean sólo un método de mercadeo dirigido a incrementar las ventas de la mercancía. En tal caso las publicaciones periódicas científicas que publican un (supuesto) trabajo de investigación de esa naturaleza no son más que un suplemento publicitario, publicidad disfrazada de ciencia. Este fenómeno de la publicidad disfrazada de ciencia se replica a lo largo y ancho de las actividades supuestamente científicas en las que nos vemos involucrados los médicos, no sólo en las investigaciones y en las publicaciones, también en las conferencias de actualización, en los simposios, en los congresos médicos y en las entrevistas a los medios de comunicación.

En una sociedad capitalista tardía, prácticamente todo puede ser transformado en mercancía, sin embargo, el slogan reduccionista de que todo puede reducirse a leyes de mercado tampoco es cierto: en las relaciones entre personas, en lo que nos debemos los unos a los otros, hay aspectos que no necesariamente tienen que ser mercancías a no ser que uno lo quiera o lo acepte (no en vano se dice que hasta la conciencia moral de un hombre puede tener un precio, aunque en tal caso se convierte uno mismo en mercadería).

Aunque en las publicaciones periódicas científicas existe un proceso de autorregulación, una serie de normas implícitas que últimamente se han tenido que hacer cada vez más explícitas precisamente para evitar que las leyes del mercado inunden y se superpongan a las normas de independencia y transparencia de las publicaciones verdaderamente científicas, diversos mecanismos, algunos de ellos diseñados supuestamente para garantizarlas, han terminado por servir de palancas para incrementar o disminuir la demanda de un cierto producto, es decir, en este caso, de una cierta publicación.

Podríamos resumir el asunto afirmando que, puesto que las publicaciones periódicas científicas son medios para distribuir el conocimiento, la demanda de estos medios 
depende de la posibilidad que tengan de demostrar que son útiles como medios de distribución del conocimiento, sin caer en la trampa de dejarse utilizar como medio publicitario.

Pero, ¿qué tan útil es Acta Médica Colombiana, qué tan útil es The Lancet? No hay manera de saberlo a ciencia cierta y primero habría que precisar la pregunta ¿qué tan útiles con respecto a qué?. Podríamos inventarnos un "Indicador Clínico-Práctico" y decir que una revista científica médica es más útil cuanto más se la lea y cuanto más se apliquen en la práctica clínica diaria los conocimientos divulgados en esa publicación. Pero ¿cómo vamos a medir ese índice aparentemente tan útil?. En la teoría el índice parece inmejorable, pero en la práctica la medición es imposible. Se podrían hacer algunas estimaciones basadas en encuestas, pero no creo que una simple recopilación de opiniones fuera de mucha utilidad o se acercara siquiera a lo que buscábamos con el pretendido "Indicador Clínico-Práctico". Baste pensar en el médico que para la situación específica de un paciente prescribió el medicamento " $x$ " o utilizó la técnica quirúrgica "y" o recomendó " $z$ " modificación en el estilo de vida. Dicho médico se enteró de las bondades de "x", "y" o "z" ¿porque un profesor se lo enseñó?, ¿porque un colega se lo comentó?, ¿porque el visitador médico se lo dijo mientras le regalaba un lapicero?, ¿porque lo vio en la televisión?, ¿porque lo leyó en New England Journal of Medicine o en Acta Médica Colombiana?, ¿por todas las anteriores?, ¿por ninguna de las anteriores pues fue el propio paciente quien se lo sugirió porque lo leyó en un foro de la internet?. A lo mejor el médico en cuestión ni siquiera sabe responder por qué recomendó "x", "y" o "z", aunque pueda afirmar que simplemente lo sabía y que sabía, además, que era la mejor opción para el paciente, aunque no recuerda dónde la aprendió.

Como puede verse, el problema de este hipotético "Indicador Clínico-Práctico" es que está basado en una serie de eventos posibles, pero todos ellos subjetivos y que no podemos objetivar. Eludir toda esa carga de subjetividad al intentar medir la importancia de una publicación periódica científica implica construir un indicador en el que no estén presentes ítems de carácter subjetivo.

En bibliometría, una de las ramas de mayor crecimiento al interior de la cienciometría [cuya fundamentación filosófica podría encontrarse al interior de la epistemetría (4)], quizás el indicador de citaciones más difundido es el Índice de Impacto o Factor de Impacto (del inglés Impact Factor) calculado cada año por el ISI (Institute for Scientific Information -http://wokinfo.com/-) de la empresa Thomson Reuters y publicado en el Journal Citation Reports (http://science. thomsonreuters.com/info/preorder-jcr/). Dicho índice es absolutamente objetivo: no se basa en si subjetivamente nos pareció útil o no una determinada publicación periódica científica, sino que se basa en el número de citaciones que los artículos publicados en dicha publicación durante los dos años previos al año que se está evaluando han conseguido en todas las revistas (5). Por ejemplo, si fuéramos a determinar el Índice de Impacto de Acta Médica Colombiana para el año
2010, habría que esperar primero a que terminara el año y tener a mano todas las publicaciones científicas de ese año (obviamente no es posible revisarlas todas, pero para el caso del índice que nos ocupa basta con las que están indizadas en la base de datos del ISI), después tendríamos que buscar cuántas veces los artículos de Acta Médica Colombiana publicados durante los años 2008 y 2009 fueron citados en los artículos aparecidos en 2010 en todas las revistas de la base de datos del ISI (incluyendo Acta Médica Colombiana, si tuviésemos el gusto de pertenecer a dicha base de datos) y dividirlo por el número total de artículos publicados en Acta Médica Colombiana durante los años 2008 y 2009. El numerador del Índice de Impacto es el número de veces que durante el año en que se realiza la evaluación fueron citados en todas las revistas de la base de datos los artículos publicados durante los dos años previos en la revista que se evalúa y el denominador es el número de artículos publicados por la revista que se evalúa durante esos mismos dos años. Si en 2010 se citaron en 50 artículos los artículos publicados en Acta Médica Colombiana durante 2008 y 2009 y Acta Médica Colombiana publicó en total 50 artículos de 2008 a 2009, el Índice de Impacto es 1 , si sólo se citaron en 10 el Índice de Impacto es 0.2 y si se citaron en 200 el Índice de Impacto es 4. Cuando termine el año 2011 y se vaya a establecer el índice de impacto para ese año, se tomarán en cuenta las publicaciones de 2009 y 2010 citadas durante 2011 (o sea que las publicaciones de 2009 serán tenidas en cuenta en dos ocasiones: al determinar el Índice de Impacto de 2010 y al determinar el de 2011).

Como puede verse el Índice de Impacto es un indicador que mide la utilidad de una publicación periódica científica no con base en la posibilidad de aplicar en la práctica los artículos que publica (evaluación completamente subjetiva) sino con base en la cantidad de citas que generan los artículos que publica. Se trata de una manera indirecta de indagar qué tanto influye una revista periódica que publica artículos de investigación en investigaciones que, a su vez, serán publicadas en publicaciones periódicas científicas. La situación es un poco tautológica, hay que admitirlo, nada más parecido al club del mutuo elogio: yo soy importante porque usted lo dice y usted es importante porque yo lo digo. El problema es que las autocitaciones están permitidas (el club del mutuo elogio en su versión narcisista) y que es posible infectar el sistema (el club del mutuo elogio en su versión contagiosa) no con un virus informático (un hacker seguramente podría ingresar a la base de datos del ISI y modificar los datos, pero el truco no reflejaría la realidad) sino con un virus bibliométrico ( $\sin$ falsear ninguna base de datos y generando resultados absolutamente objetivables y ciertos).

La más reciente epidemia por un virus bibliométrico comenzó en 2008, pero sólo se detectó a mediados de 2010 cuando Thomson Reuters publicó a través del Journal Citation Reports los Índices de Impacto para el año 2009 (6). Si uno observa de manera desprevenida el informe se encuentra con una larga lista de 7.387 publicaciones periódicas, desde 
4OR (publicada en inglés, en Alemania, por Springer Heildelberg y dedicada a la difusión de investigaciones en ciencias administrativas), hasta Zygote (publicada en inglés, en la Gran Bretaña, por Cambridge University Press y dedicada a la biología reproductiva desde el enfoque de la biología celular), pasando por publicaciones del calibre de Acta Carsologica (publicada en inglés, en Eslovenia, por la Academia Eslovena de Artes y Ciencias y dedicada a la divulgación de estudios multidisciplinarios, no sólo geomorfológicos sino también hidrológicos, climatológicos, espeleológicos y ecológicos sobre el Carso), Interface Science (dedicada a la divulgación de investigaciones sobre la estructura y propiedades de las interfaces que existen al interior de los sólidos) o de The American Malacology Bulletin (que ya habrán adivinado a qué se dedica), cada una de ellas acompañada del total de citaciones alcanzadas durante 2009 por los artículos que publicaron en 2007 y 2008, y del Índice de Impacto de 2009. Puesto que uno va a buscar primero a los viejos amigos, inicialmente no nota absolutamente nada raro: Nature tiene un Índice de Impacto de 34, similar al de otros años, New England Journal of Medicine tiene un poco más de 47 , como siempre, y así sucesivamente. Se respira ese aire de normalidad y estancamiento que siempre se encuentra al leer un informe periódico en el que por lo general nada cambia, pues si se programa la base de datos para que reordene las revistas no por orden alfabético sino por rango, del mayor Índice de Impacto al menor, y se toma uno el trabajo de revisar también los informes de 2006, 2007 y 2008 , es posible demostrar que los primeros 20 puestos en todos los años nunca han salido de las manos de las mismas 30 revistas... con una excepción, que constituyó la sorpresa del informe de 2009.

En 2009 el primer lugar en el Índice de Impacto continúa siendo para A Cancer Journal for Clinicians, que ha estado en el mismo puesto desde 2006, pero el segundo lugar ya no es para New England Journal of Medicine, que lo había detentado durante 2006, 2007 y 2008 y pasa al tercer lugar, desplazada del segundo por Acta Crystallographica-Section $A$, una revista perfectamente desconocida excepto por superespecialistas en su campo, que en 2008 se encontraba en el rango 2.118 entre 6.620 revistas, en 2007 en el rango 1.408 entre 6.426 y en el 2006 en el rango 2.143 entre 6.166 .

La sorpresiva noticia de esta subversión en lo que ya era dable considerar el orden natural de las cosas es menos interesante que la historia de cómo se dio, así que me extenderé un poco más: SHELX es un programa computadorizado que, con diversas actualizaciones, vienen empleando desde 1970 los cristalógrafos en el curso habitual de su trabajo de determinación de la estructura de cristales. George Sheldrick, un cristalógrafo de la Universidad de Gotinga que ha colaborado en el desarrollo de SHELX desde sus comienzos, publicó en 2008 en Acta Crystallographica-Section A un artículo de revisión titulado A short history of SHELX (Una breve Historia de SHELX) (7) y en la introducción a su revisión histórica incluyó el siguiente virus bibliométrico: This paper could serve as a general literature citation when one or more of the open-source SHELX programs (and the Bruker AXS version SHELXTL) are employed in the course of a crystalstructure determination (este artículo podría servir como una cita de literatura general cuando se empleen uno o mas de los programas SHELX de código abierto o SHELXTL, la versión AXS de Bruker, en el proceso de determinación de la estructura de un cristal). Disfrazando de posibilidad una recomendación, propone que cada vez que alguien realice un trabajo de investigación en el que se utilice SHELX, en lugar de simplemente constatar en "Material y Métodos" que se utilizó alguna de las variantes de SHELX, se cite este artículo como referencia. El contagio y el periodo de incubación fueron rápidos: durante el año 2009 Una breve Historia de SHELX consiguió más de 6.600 citaciones incrementando el Índice de Impacto de Acta Crystallographica-Section A de 2.051 en 2008 a 49.926 en 2009. Marie McVeigh, directora del Journal Citation Reports y directora de políticas bibliométricas en Thomson Reuters, afirmó poco después que "sin otro artículo tan importante como Una breve Historia de SHELX, para el próximo informe Acta CrystallographicaSection A volverá a su Índice de Impacto habitual entre 1.5 y 2.5" (8). Esa afirmación es falsa: cada día se publican en el mundo entre veinte y treinta investigaciones cristalográficas que han utilizado SHELX y el año 2010 no tiene por qué ser la excepción, así que, con toda probabilidad, la Breve Historia de Sheldrick infectará durante 2010 por lo menos otros 6600 artículos de cristalografía y en junio de 2011, cuando estemos leyendo el Journal Citation Reports sobre 2010, veremos todavía a Acta Crystallographica-Section A por lo menos entre las cinco primeras publicaciones periódicas científicas en cuanto al Índice de Impacto. En 2012 sí cambiará la situación, pues el Índice de Impacto tomará en cuenta para informar sobre el año 2011 solamente los artículos publicados en los dos años previos, 2009 y 2010, y habrá desaparecido de la historia de la bibliometría el brote epidémico desatado por la publicación de Sheldrick.

El Índice de Impacto ha recibido muchas críticas, incluso desde antes del "exitoso" virus bibliométrico. Algunas de dichas críticas provienen de teóricos de la bibliometría (9) y otras se hacen con el fin de avalar nuevos índices bibliométricos supuestamente sin los problemas del Índice de Impacto (pero con otros) (10), pero hay quien dio un paso más allá de la mera crítica y alcanzó la infamia porque entró en acción torpedeando el índice desde adentro, no ya mediante un virus bibliométrico sino mediante una especie de metástasis bibliométrica. En 2007 los editores de Folia Phoniatrica et Logopaedica, descontentos con el hecho de que algunas universidades, especialmente Europeas, habían comenzado a distribuir los recursos económicos a sus facultades y departamentos con base en el Índice de Impacto de las revistas que aceptaban para publicación los trabajos de sus docentes e investigadores, decidieron sentar su protesta demostrando en la práctica que era posible modificar el Índice de Impacto con sólo autocitarse. En consecuencia, 
escribieron un artículo (11) en el que simplemente cuentan que el Índice de Impacto no les parece la mejor manera de medir la importancia de una publicación periódica y mucho menos de distribuir los recursos universitarios y agregan que la revista ha publicado 67 artículos en los últimos dos años. A continuación en varias tablas muestran el país de origen de las investigaciones que finalmente dieron origen a los artículos, cuántos y cuales artículos de los 67 están dedicados a problemas de la voz, cuántos a problemas del lenguaje, cuántos a trastornos de la deglución, etc. pero, obviamente, al nombrar cada uno de los artículos los citan en la bibliografía. El resultado final es un artículo de la revista que cita todos los artículos publicados por la revista en los dos años previos por una sola vez, pero obviamente al hacerlo se le suman 67 unidades al numerador del Índice de Impacto y puesto que el denominador es 67 el Índice de Impacto para el año 2007 sería como mínimo 1. En realidad fue 1.44, lo cual significa que sin esos artículos malignos produciendo metástasis desde los números de 2005 y 2006 a uno de los números de 2007, el Índice de Impacto habría estado incluso por debajo del 0.66 que había alcanzado el año anterior. Posiblemente mediante esta maniobra, advertida previamente y realizada a plena luz del día, se incrementaron proporcionalmente los ingresos de los profesores del Laboratorio de Investigación de la Voz en la Universidad de Groningen, en Holanda, y del Laboratorio de Biofísica de la Universidad Palacký, en la República Checa, pero Folia Phoniatrica et Logopaedica murió para la bibliometría pues fue sancionada por el Journal Citation Reports (junto con otras 25 revistas) excluyéndola de la publicación por tiempo indefinido hasta tanto demuestren que no están abusando de la autocitación. La autocitación no es en sí misma un acto condenable, sería más condenable exigirle a New England Journal of Medicine que no publique artículos que citen artículos publicados en New England Journal of Medicine durante los dos años previos; de hecho la autocitación también se tiene en cuenta al calcular el Índice de Impacto, es decir, para calcular el Índice de Impacto de Acta Médica Colombiana para 2010 se tendrán en cuenta no sólo las citas en otras revistas sino también el número de veces que Acta Médica Colombiana cite durante 2010 los artículos publicados en la propia Acta Médica Colombiana durante 2008 y 2009. El problema, según Thomson Reuters, es de abuso de autocitación: Folia Phoniatrica et Logopaedica y las otras revistas excluidas del Índice de Impacto en 2008 tenían una tasa de autocitación excepcionalmente alta, en algunos casos se habían autocitado por encima de $90 \%$, es decir, citaban en números subsiguientes más de $90 \%$ de los artículos publicados en los números previos (12). Aunque en ninguna parte dicen qué es una tasa de autocitación excepcionalmente alta, sabemos al menos que Folia Phoniatrica et Logopaedica lo hizo abiertamente y como medida de protesta, las otras 25 revistas que fueron sancionadas con la exclusión de la base de datos del Journal Citation Reports lo venían haciendo a hurtadillas porque querían aumentar su Índice de Impacto.

Sin embargo, con todas las críticas que se le puedan hacer al Índice de Impacto, aún no tenemos nada mejor. Parafraseando la frase de Churchill con respecto a los peligros de la democracia ["la democracia es la peor forma de gobierno excepto todas las otras formas" (13)], tendríamos que decir que hasta el momento el Índice de Impacto es el peor de los indicadores bibliométricos excepto todos los demás. Estamos a la espera de lo que nos depare el futuro inmediato con las nuevas propuestas en bibliometría. Esperamos que no esté muy lejano el día en que podamos establecer la utilidad de indicadores que miden el impacto de un artículo y no el de la revista completa, como Article-level Metrics de la Public Library of Science a través de su revista en red $P L O S O N E$ (14)-, y que tampoco esté lejano el día en que podamos valernos de manera eficaz de indicadores que miden la productividad y el impacto de la producción científica individual de un investigador, como el h-Index (15) [o su variante el $g$-index que mide el impacto a largo plazo de la producción científica de un investigador individual (16)]. Tampoco resulta impensable que pronto lleguemos a utilizar indicadores derivados de motores de búsqueda como el de Google Scholar, que permiten identificar los artículos subsiguientes que citan un artículo publicado previamente (17). De igual manera, si definitivamente las publicaciones periódicas científicas van a migrar todas hacia la red, muy pronto comenzaremos más bien a evaluarlas mediante indicadores de impacto similares a los indicadores de impacto de páginas en la internet como PageRank(18). Article-level Metrics llama la atención porque además de medir el impacto de un artículo individual con base en el número de citaciones que genere en revistas indizadas en bases de datos como PubMed, pretende tomar en cuenta todos aquellos datos que quedan almacenados en la red que implican que un artículo científico es útil (en la medida en que ha sido leído y evaluado por sus lectores): visitas al artículo en la páginas de la red (HTML), descargas del artículo de su sitio de almacenamiento en la red (PDF y XML), marcadores (bookmarkers) que dirigen hacia el artículo en redes sociales de manejo e intercambio de bibliografía (social citation services) como CiteULike (http://www.citeulike.org/) o Connotea (http:// www.connotea.org/) y, finalmente, puntuaciones, comentarios y notas dejadas por los lectores de cada artículo en las páginas que dejan abierta esta posibilidad.

Bueno, pero todo lo antedicho no es todavía para Acta Médica Colombiana un problema real, en Acta Médica Colombiana, aunque estamos indizados en bases de datos regionales muy importantes (Publindex, SciELO, BIREME, $L I L A C S)$ y recientemente, gracias a la gestión de nuestro director emérito, el Dr. Paulo Emilio Archila, hemos sido aceptados en Redalyc, aún no estamos en ninguna de las grandes bases de datos globales (ISI, Scopus, Medline, PubMed,NLM). De hecho ni siquiera tenemos el problema de la autocitación, ojalá lo tuviéramos; la mayoría de las revisiones de tema que recibimos están plagadas de citas 
sobre estadísticas de los Estados Unidos de América. ¿En dónde están nuestras propias estadísticas? La triste realidad es que ni siquiera nos citamos a nosotros mismos. La gran mayoría de las veces por desconocimiento (no hace mucho se publicó en Acta Médica Colombiana una Presentación de Casos en la que se afirmaba que era esta la primera vez en nuestro país que se publicaba el caso clínico en cuestión cuando diez años antes se había publicado en la propia Acta Médica Colombiana un caso similar). A veces no se cita por amnesia, hemos olvidado quién trabajó en problemas científicos similares y no nos tomamos el trabajo de buscar. Otras veces, peor aún, no citamos por criptomnesia, como denominó Théodore Flournoy a aquellos recuerdos que aparecen falsamente en nuestra mente no como si fueran recuerdos en la memoria sino como si fueran ideas nuevas, recién halladas o creadas por nuestra propia mente (19). Algunas veces, no citamos por envidia ¿cómo vamos a darle semejante crédito a alguien que trabaja en nuestro mismo campo de investigación y, por lo tanto, no es más que nuestro competidor?.

En los próximos meses Acta Médica Colombiana hará una profunda reingeniería de la página en Internet. En primer lugar se hará el esfuerzo de digitalizar todo el contenido de los 35 años que llevamos de publicación con el fin de que este material esté siempre disponible, no sólo en la página, sino accesible a todos los motores de búsqueda importantes con que cuenta la red. Para el efecto se ha contratado un asesor en indización y cienciometría y se ha contratado también un administrador de la página en la red. Ambos ayudarán a que este proceso se dé de la mejor manera posible. Se crearán todos los contadores de visitas necesarios para que día a día se pueda dar una medición de la utilidad de Acta Médica Colombiana: cuantos artículos se consultan en red, cuántos se bajan en PDF, cuántos se comentan, cuántos se citan en otras revistas o en blogs o en otras páginas de la red. Se contará con un nuevo alojamiento en la red (hosting), la página de Acta Médica Colombiana será rediseñada por completo por una compañía experta en publicaciones periódicas científicas en la red y se crearán noticias de los artículos que Acta Médica Colombiana publica en redes sociales como Facebook y Twitter y, obviamente, se crearán los vínculos en redes de citación como CiteULike y Connotea que redirijan a sus usuarios hacia nuestra revista. El plan es posicionar Acta Médica Colombiana frente a los nuevos retos planteados por la era digital. Los motores de búsqueda y las bases científicas globales cada vez miran más a América Latina y a los países del tercer mundo en la medida en que aquí existe investigación original sobre patologías, procesos y ambientes que no existen en el primer mundo. Nuestra investigación puede y debe ser una investigación autóctona y de calidad sin que necesariamente sea una investigación amarrada a las grandes multinacionales ni a los grandes estudios multicéntricos cuyos protocolos llegan a nuestro medio ya prefabricados solamente para que nuestros comités de ética de la investigación les den el aval y nosotros aportemos los pacientes. Aspiramos a conseguir, en los próximos dos años, formar parte de las bases de datos globales más importantes (ISI, Scopus, MedLine, PubMed). Sea este el momento para invitarlos a que nos citemos a nosotros mismos ( Phoniatrica et Logopaedica).

\section{Referencias}

1. Young NS, Ioannidis JPA, Al-Ubaydli O. Why Current Publication Practices May Distort Science. PLoS Med 2008; 5(10): e201. doi:10.1371/journal. pmed.0050201

2. Smith A. An Inquiry into the Nature and Causes of the Wealth of Nations. Petersfield, Hampshire: Harriman House; 2007: pp 36-42.

3. Smith A. The Theory of Moral Sentiments. New York; Kosimo Classics; 2007: pp 181-189.

4. Rescher N. Epistemetrics. Cambridge; Cambridge University Press; 2006.

5. Garfield E. The Thomson Reuters Impact Factor. http://thomsonreuters.com/products services/science/free/essays/impact factor/. Consultado el 3 de septiembre de 2010 .

6. 2009 Journal Citation Reports ${ }^{\circledR}$ Science Edition (Thomson Reuters, 2010)

7. Sheldrick GM. A short history of SHELX. Acta Cryst 2008; A64: 112-122.

8. Grant B. New impact factors yield surprises. The Scientist: Magazine of life sciences. http://www.the-scientist.com/blog/display/57500/\#ixzz129MQk8Jr. Consultado el 3 de septiembre de 2010.

9. Garfield E. Dispelling A Few Common Myths About Journal Citation Impacts. The Scientist 1997, 11(3):11.

http://www.the-scientist.com/article/display/17383/\#ixzz12BKrULVl. Consultado el 3 de septiembre de 2010

10.Dolgin E. New impact metric. http://www.the-scientist.com/blog/ display/55343/\#ixzz12BNph8SW. Consultado el 3 de septiembre de 2010

11. Schuttea HK,vec JG. Reaction of Folia Phoniatrica et Logopaedica on the Current Trend of Impact Factor Measures. Folia Phoniatr Logop 2007;59:281-285.

12. Journal Citation Reports ${ }^{\circledR}$ Notices. http://admin-apps.isiknowledge.com/JCR/ static html/notices/notices.htm. Consultado el 3 de septiembre de 2010.

13. Churchill W. Speech in the House of Commons .The Official Report, House of Commons (5th Series), 11 November 1947, vol. 444, cc. 206-207.

14. Article-Level Metrics Information. http://www.plosone.org/static/almInfo.action. Consultado el 10 de octubre de 2010.

15. Hirsch JE. An index to quantify an individual's scientific research output. PNAS 2005; 102 (46): 16569-16572.

16. Egghe L. Theory and practise of the g-index. Scientometrics 2006; 69 (1) 131-152.

17. Noruzi A. Google Scholar: The New Generation of Citation Indexes. Libri 2005; 55 (4): 170-180.

18. Page L. PageRank: Bringing Order to the Web. http://web.archive.org/ web/19991010145029/www-pcd.stanford.edu/ page/papers/pagerank/. Consultado el 3 de septiembre de 2010.

19. Porge E. Cryptomnesia. En De Mijolla A (Ed.) International Dictionary of Psychoanalysis. Gale Cengage, 2005. eNotes.com. 2006. http://www.enotes.com/ psychoanalysis-encyclopedia/cryptomnesia. Consultado el 3 de septiembre de 2010 . 